\title{
KELELAHAN KERJA PADA OPERATOR CONTAINER CRANE DI PT. X
}

\author{
FATIGUE THAT CAUSED BY WORK ON CONTAINER CRANE \\ OPERATORS AT THE PT. X
}

\author{
Nesya Yulita Anindya \\ PT. Citra Perkasamas Enginindo \\ E-mail: nesyaanindya930@yahoo.com
}

\begin{abstract}
Fatigue that caused by working activity is a problem which every workers had already experienced it. Fatigue condition that happened on workers usually occurs differently. Fatigue that caused by working activity had some determinant factors. Container Crane operator was a job that had an important role on container handling process at PT. X. This handling process occurred 24 hours/day, and divided into 3 shift work morning, evening and night shift. Two operator operated a CC for every 8 work hour by turns. The purpose of this research was to describe fatigue that caused by working activity on CC operator at PT. X. This research was a observational descriptive study that describe work fatigue that caused by working activity and determinant factor on container crane operators. Population of this research was all 51 CC operators. Descriptive analytic showed in form of frequency, percentage, and cross tabulation. The result showed that fatigue on CC operators mostly was a low fatigue level (90.2\%), and the rest (9.8\%) was a medium fatigue level. Workers that experienced medium fatigue level mostly on evening shift (40\%) Night shift workers tend to experienced fatigue that caused by working. Lenght of sleep time $\leq 6.5$ hours tend to experienced fatigue caused by working.
\end{abstract}

Keywords: fatigue work, operator, shift work

\begin{abstract}
ABSTRAK
Kelelahan kerja adalah masalah yang sering dialami oleh pekerja. Kondisi kelelahan yang terjadi biasanya berbeda antar individu. Kelelahan yang terjadi dapat dipengaruhi oleh banyak faktor. Operator container crane adalah salah satu pekerja yang ada di PT. X dan mempunyai peranan penting dalam proses bongkar muat petikemas. Proses bongkar muat petikemas ini melayani 24 jam dalam sehari dan dibagi menjadi 3 shift kerja yaitu shift pagi, shift sore dan shift malam. Dalam setiap container crane dijalankan oleh 2 operator secara bergantian. Tujuan penelitian ini adalah untuk mengetahui adanya gambaran kelelahan kerja pada operator container crane di PT. X. Penelitian ini adalah penelitian observasional deskriptif yang menggambarkan tingkat kelelahan kerja operator container crane. Populasi pada penelitian ini adalah seluruh operator container crane berjumlah 51 operator. Hasil yang didapatkan dianalisis secara deskriptif dan disajikan dalam bentuk tabel, persentase dan tabulasi silang. Hasil penelitian menunjukkan kelelahan yang terjadi pada operator container crane mayoritas adalah kelelahan rendah sebanyak $90,2 \%$ dan kelelahan sedang sebanyak $9,8 \%$. Paling banyak operator yang mengalami kelelahan kerja sedang adalah shift malam sebanyak $40 \%$. Shift kerja malam cenderung untuk mengalami kelelahan kerja. Lama waktu tidur $\leq 6,5$ jam cenderung mengalami kelelahan kerja.
\end{abstract}

Kata kunci: kelelahan kerja, operator, shift kerja

\section{PENDAHULUAN}

Keselamatan dan kesehatan kerja dalam suatu masalah yang penting dalam setiap proses produksi. Tidak terkecuali untuk perusahaan yang menyediakan jasa bongkar muat barang. Hal ini dilakukan untuk mencegah dan mengurangi terjadinya kecelakaan kerja.

Kecelakaan yang terjadi bukan karena kebetulan tetapi ada penyebab terjadinya kecelakaan. Data dari International Labour Organization (ILO) (2013) satu pekerja di dunia meninggal setiap
15 detik dikarenakan kecelakaan kerja dan 160 pekerja mengalami sakit akibat kerja. Pada tahun 2015 jumlah kecelakaan kerja berdasarkan BPJS Ketenagakerjaan mencapai 110.285 dan jumlah santunan yang dibayarkan mencapai Rp. 661 miliar. Pada April 2016 terjadi kasus sebanyak 33.151 kasus.

Kecelakaan yang terjadi dapat memberikan kerugian bagi pekerja, institusi dan pemerintahan. Kerugian kecelakaan dapat tergambar dari biaya yang dikeluarkan seringkali sangat besar. Padahal 
biaya kerugian tersebut bukan hanya menjadi beban suatu perusahaan tetapi juga beban masyarakat dan negara secara keseluruhan (Suma'mur, 2009). Kecelakaan kerja dapat terjadi karena tindakan manusia yang tidak aman serta keadaan lingkungan yang tidak aman. Kecelakaan karena faktor manusia ini yakni mencapai $80-85 \%$.

Faktor penyebab kecelakaan yang disebabkan oleh manusia diantaranya yaitu menurunnya tingkat kewaspadaan akibat terjadinya kelelahan kerja. Setyawati (2010) kelelahan kerja memberikan kontribusi lebih dari 60\% kejadian kecelakaan kerja yang ada di tempat kerja. Menurut Tarwaka (2015) kelelahan kerja adalah suatu perlindungan dari tubuh untuk mempertahankan kondisi tubuh dari kerusakan yang lebih lanjut dan kemudian akan terjadi pemulihan setelah istirahat. Menurut Suma'mur (2009) kelelahan didefinisikan sebagai adanya penurunan ketahanan dan daya tubuh untuk melakukan suatu pekerjaan. Kelelahan kerja yang terjadi tidak hanya dialami setelah bekerja tetapi bisa juga dialami pada saat sebelum bekerja. Kelelahan kerja menyangkut pada adanya penurunan kinerja fisik, timbulnya perasaan lelah, motivasi kerja yang turun, dan juga menurunnya produktivitas kerja dari tenaga kerja.

Kondisi kelelahan yang terjadi biasanya berbeda antar individu, hal ini tergantung dari energi yang diperlukan oleh tubuh. Jumlah energi yang diperlukan oleh tubuh ini tergantung pada aktivitas kerja yang dilakukan oleh tubuh. Apabila aktivitas kerja yang dilakukan cukup ringan, metabolisme penyediaan energi dapat diproses secara aerobik. Hal ini karena tersedianya oksigen yang cukup memadai. Aktivitas kerja yang dilakukan semakin meningkat, maka diperlukannya penambahan energi secara anaerobik. penambahan energi ini diproses dari pemecahan simpanan glikogen yang ada dalam otot sebagai bahan energi. Konsentrasi glikogen dalam otot menjadi menurun dan konsentrasi asam laktat meningkat. Adanya konsentrasi asam laktat yang meningkat maka akan menimbulkan kelelahan (Santoso, 2013).

Terdapat dua jenis kelelahan yang terjadi yaitu kelelahan otot dan kelelahan umum. Kelelahan kerja otot ditandai dengan melemahnya kondisi otot, sedangkan kelelahan umum ditandai dengan adanya perasaan lelah, adanya perasaan berat di kepala, timbulnya rasa kantuk, dan lain sebagainya.
Kelelahan kerja ini dapat diukur dengan berbagai cara, hanya saja belum ada cara untuk mengukur tingkat kelelahan kerja secara langsung. Pengukuran kelelahan yang dilakukan hanyalah berupa indikator yang menunjukkan terjadinya kelelahan yang disebabkan akibat kerja (Tarwaka, 2015).

Menurut ILO tahun 2013 dua juta pekerja yang meninggal dunia yang dikarenakan kecelakaan kerja ini disebabkan oleh faktor kelelahan kerja yang dialami tenaga kerja. dari penelitian yang dilakukan bahwa $32,8 \%$ dari sample penelitian mengaku mengalami kelelahan. pada TNI Angkatan Udara (AU) di Amerika Serikat 60\% kecelakaan kerja yang terjadi dikarenakan oleh kelelahan kerja. Pada penelitian Arini dan Dwiyanti (2015), juga menyatakan operator pengumpul tol mengalami kelelahan kerja yang berbagai macam mulai dari kelelahan kerja ringan sebanyak (50,7\%), kelelahan kerja yang sedang $(35,8 \%)$, dan juga kelelahan yang tinggi $(13,4 \%)$, penelitian yang dilakukan Faiz (2014) juga menyatakan adanya kelelahan ada operator SPBU sebanyak 52,4\%. Adanya kelelahan kerja yang berbeda pada setiap individu, hal ini juga yang dialami oleh operator container crane dalam perusahaan jasa bongkar muat barang.

Kelelahan kerja yang terjadi dapat disebabkan oleh beberapa faktor. Mulai dari kondisi lingkungan kerja yang kurang memadai, beban kerja yang tinggi, cara dan sikap kerja yang kurang benar, intensitas dan lamanya kerja fisik, kondisi tenaga kerja yang berbeda, adanya rotasi kerja, dan lain sebagainya. Kelelahan juga dapat terjadi karena adanya gangguan tidur yang dialami pekerja. Hal ini dipengaruhi oleh kurangnya waktu untuk tidur dan juga gangguan pada circadian rhythms akibat adanya shift kerja (Hidayat, 2011).

Shift kerja merupakan suatu sistem yang mengatur mengenai jam kerja, tenaga kerja dapat saling menggantikan satu sama lain dalam bidang yang sama setelah periode waktu tertentu yang sebelumnya telah disepakati, dan hal ini bertujuan untuk tetap melakukan proses produksi selama 24 jam. Shift kerja merupakan periode waktu dalam suatu kelompok tenaga kerja dijadwalkan bekerja pada tempat tertentu. Durasi waktu yang disepakati oleh manajemen umumnya berdurasi 8 jam atau 12 jam setiap shift kerja.

Pada komunitas Inggris menyebutkan bahwa $25 \%$ wanita dan $20 \%$ laki-laki mengeluh merasakan lelah. Di sektor maritim terdapat 279 kecelakaan, 
kelelahan menyumbang $16 \%$ kecelakaan tanpa cedera dan juga 33\% kecelakaan yang menyebabkan adanya luka-luka.

PT. X merupakan suatu fasilitas pelabuhan yang bergerak di bidang bongkar muat petik emas yang berada di kota Surabaya. PT. X dalam melakukan kegiatannya, membutuhkan suatu alat untuk membantu dalam proses bongkar muat barang. Salah satu alat yang digunakan untuk melakukan bongkar muat barang adalah container crane (CC). Alat ini berfungsi untuk membongkar atau memuat peti kemas dari kapal ke dermaga atau sebaliknya. Pada Steenken dan Stahlbock (2004) kapal yang berisi peti kemas yang mendekat ke dermaga akan bersandar dan melepas jangkar nya untuk mempertahankan posisinya, kemudian container crane (CC) akan menjalankan trolley untuk mengaitkan adaptor pada sisi peti kemas yang kemudian peti kemas ini diangkat. Sehingga, peran pekerja sebagai operator $\mathrm{CC}$ ini sangat penting. Pada saat mengoperasikan container crane pada umumnya operator ini berada dalam kondisi awkward posture yang berlangsung lama, bekerja pada tempat terbatas, dan shift kerja yang mungkin dapat mengganggu kesehatan operator (Fadda dkk, 2015).

Proses bongkar muat peti kemas di PT. $\mathrm{X}$ dilakukan 24 jam dalam sehari, dengan mempekerjakan pekerja dengan shift kerja yaitu pada shift pagi, shift sore dan shift malam. Salah satu pekerja yang bekerja dengan shift adalah operator CC. Operator CC bekerja selama 8 jam per hari dengan bergantian untuk mengoperasikan alat. Satu alat container crane dioperasikan oleh dua operator secara bergantian selama 4 jam kerja. Tujuan dari penelitian ini adalah untuk mempelajari gambaran tingkat kelelahan kerja pada operator container crane di PT. X.

\section{METODE}

Penelitian ini termasuk penelitian observasional deskriptif, yaitu untuk mendeskripsikan kelelahan kerja yang terjadi pada operator CC. Pada penelitian ini termasuk penelitian lapangan karena kegiatan penelitian dilakukan langsung pada tempat kerja. Populasi dalam penelitian ini adalah operator CC yang berjumlah 68 orang. Operator CC yang bersedia untuk menjadi responden adalah 51 orang operator CC.

Variabel yang diteliti dalam penelitian ini adalah kelelahan kerja yang dialami oleh operator $\mathrm{CC}$ dengan melakukan pengukuran menggunakan
Industrial Fatigue Research Committee dan dikategorikan dalam 4 skala likert yaitu 0-21 kelelahan rendah, 22-44 kelelahan sedang, 45-77 kelelahan tinggi, 68-90 kelelahan sangat tinggi. Shift kerja dibedakan menjadi: (a) shift malam (b) shift sore (c) shift pagi. Lama waktu tidur operator CC yang dikategorikan menjadi dua yaitu (a) $\leq 6,5$ jam dan (b) $>6,5$ jam.

Data yang dikumpulkan dalam penelitian ini adalah data primer. Data primer adalah data yang didapat dari hasil wawancara dan pengukuran kelelahan kerja operator CC. Wawancara yang dilakukan ini menggunakan panduan kuesioner untuk mengetahui karakteristik individu operator CC.

Instrumen dalam penelitian ini adalah pengukuran kelelahan menggunakan alat ukur yaitu Industrial Fatigue Research Committee yang telah diadaptasi dalam bahasa Indonesia serta kuesioner untuk mengetahui identitas responden yang meliputi umur, status pernikahan, tingkat pendidikan, masa kerja, lama waktu tidur dan lama kerja. Cara pengukuran dan pengumpulan data yakni dengan wawancara menggunakan kuesioner yang telah disediakan.

Data yang didapatkan dari hasil pengukuran dan wawancara kemudian akan dianalisis secara deskriptif dengan mendeskripsikan kelelahan kerja dan faktor yang memengaruhi kelelahan kerja tersebut. Data disajikan dalam bentuk frekuensi, persentase, dan tabulasi silang.

\section{HASIL}

PT. X merupakan terminal petikemas yang bertaraf internasional di Surabaya. PT. X pertama kali beroperasi pada tahun 1992. PT. X dalam tahun-tahun pengoperasiannya telah memiliki reputasi sebagai terminal petikemas yang efisien dan efektif terhadap biaya yang mampu melayani kebutuhan masyarakat pelayaran dan juga para importir dan eksportir di wilayah Indonesia Bagian Timur. Lokasi yang strategis membuat PT. X telah banyak melayani sebagian besar perusahaan pelayaran domestik.

Beberapa fasilitas yang terdapat di PT. X adalah dermaga Internasional yang mempunyai luas 5 ha, dermaga domestik seluas 2,25 ha, lapangan penumpukan Internasional, lapangan penumpukan domestik, area behandle (pemeriksaan bea cukai), penumpukan peti kemas reefer, pergudangan dengan luas total $10.00 \mathrm{~m}$ dan juga pergudangan untuk 
barang berbahaya, jalur kereta api yang terdapat 2 jalur sepanjang $420 \mathrm{~m}$. Peralatan yang digunakan antara lain container crane, man cage 20', man cage 40', Rubber Tyred Gantry Cranes, reach stackers, sky stackers, diesel forklifts, side loader, electric forklifts, side loader, electric forklift, double drop deck 40', hand trucks, chassis, dolly system.

Di antara peralatan yang digunakan untuk melakukan bongkar muat peti kemas yaitu container crane. Alat ini berfungsi untuk memindahkan peti kemas dari kapal ke dermaga ataupun sebaliknya. PT. X ini memiliki 11 alat container crane yang siap digunakan. Dalam menjalankan alat ini operator CC dibagi dalam 4 grup untuk pembagian shift kerja operator. Shift kerja operator CC ini dibagi menjadi 3 shift yaitu shift malam, shift sore dan shift pagi. Shift malam pada pukul $00.00-08.00 \mathrm{WIB}$, shift pagi pada pukul $08.00-16.00 \mathrm{WIB}$, sedangkan shift sore pada pukul 16.00-24.00 WIB.

Pengoperasian alat dioperasikan oleh dua operator CC secara bergantian. Pergantian untuk mengoperasikan alat ini setiap 3 hingga 5 jam dalam setiap shift. Saat melakukan pekerjaannya dibutuhkan kewaspadaan dalam memindahkan petikemas dari kapal ke dermaga ataupun dari dermaga ke kapal. Operator container crane umumnya bekerja dengan posisi duduk, membungkuk dan melihat ke bawah serta bekerja dengan posisi statis yang berlangsung lama. Hal ini dilakukan untuk memastikan bahwa kondisi pada boom container crane ini tidak bertabrakan dengan crane kapal.

Tabel 1. Distribusi Shift Kerja Operator CC di PT. X, Mei 2017

\begin{tabular}{lcc}
\hline Shift Kerja & Jumlah & Persentase (\%) \\
\hline Shift Pagi & 26 & 51,1 \\
Shift Sore & 14 & 27,5 \\
Shift Malam & 11 & 21,6 \\
\hline Total & 51 & 100 \\
\hline
\end{tabular}

Tabel 2. Distribusi Lama Waktu Tidur Operator CC di PT. X, Mei 2017

\begin{tabular}{lcc}
\hline $\begin{array}{l}\text { Lama Waktu Tidur } \\
\text { (jam) }\end{array}$ & Jumlah & $\begin{array}{c}\text { Persentase } \\
(\%)\end{array}$ \\
\hline$\leq 6,5$ & 26 & 50,9 \\
$>6,5$ & 25 & 49,1 \\
\hline Total & 51 & 100,0 \\
\hline
\end{tabular}

\section{Distribusi Shift Kerja Operator CC di PT. X}

Shift kerja pada operator CC dibagi menjadi 3 shift yaitu shift malam, shift sore dan shift pagi. Distribusi shift kerja operator pada Tabel 1. Tabel 1 menunjukkan bahwa operator yang bekerja shift pagi sebanyak 26 operator $(51,1 \%)$ hal ini karena terdiri dari dua group yang berbeda. Operator yang bekerja pada shift malam sebanyak 11 operator $(21,6 \%)$.

\section{Distribusi Lama Waktu Tidur pada Operator CC di PT. X}

Tabel 2 menunjukkan hasil bahwa operator yang memiliki waktu tidur $\leq 6,5$ jam sebanyak $50,9 \%$ dan yang memiliki waktu tidur $>6,5$ jam sebanyak $49,1 \%$. Hal ini menunjukkan bahwa perbedaan lamanya waktu tidur operator tidak jauh berbeda.

\section{Distribusi Kelelahan Kerja Pada Operator CC di PT. $X$}

Kelelahan kerja ini dibagi menjadi kelelahan rendah, kelelahan sedang, kelelahan tinggi, dan kelelahan sangat tinggi. Distribusi kelelahan kerja operator CC pada Tabel 3.

Tabel 3 menunjukkan bahwa kelelahan yang dialami oleh operator CC sebagian besar adalah kelelahan rendah yakni sebanyak 46 operator

Tabel 3. Distribusi Kelelahan Kerja Operator CC di PT. X, Mei 2017

\begin{tabular}{lcc}
\hline Kelelahan Kerja & Jumlah & $\begin{array}{c}\text { Persentase } \\
(\%)\end{array}$ \\
\hline Kelelahan Rendah & 46 & 90,2 \\
Kelelahan Sedang & 5 & 9,8 \\
\hline Total & 51 & 100,0 \\
\hline
\end{tabular}

Tabel 4. Tabulasi Silang Shift Kerja Dengan Kelelahan Kerja Operator CC di PT. X, Mei 2017

\begin{tabular}{lcccccc}
\hline \multirow{2}{*}{$\begin{array}{l}\text { Shift } \\
\text { Kerja }\end{array}$} & \multicolumn{4}{c}{ Kelelahan Kerja } & \multirow{2}{*}{ Total } \\
\cline { 2 - 5 } & \multicolumn{2}{c}{ Rendah } & \multicolumn{2}{c}{ Sedang } & & \\
\cline { 2 - 5 } & $\mathbf{n}$ & $\mathbf{\%}$ & $\mathbf{n}$ & $\mathbf{\%}$ & $\mathbf{N}$ & $\mathbf{\%}$ \\
\hline Pagi & 24 & 52,2 & 2 & 40,0 & 26 & 51,0 \\
Sore & 13 & 28,3 & 1 & 20,0 & 14 & 27,5 \\
Malam & 9 & 19,6 & 2 & 40,0 & 11 & 21,6 \\
\hline Total & 46 & 100,0 & 5 & 100,0 & 51 & 100,0 \\
\hline
\end{tabular}


(90,2\%). Operator yang mengalami kelelahan kerja sedang sebanyak 5 operator $(9,8 \%)$ sedangkan tidak ada operator yang mengalami kelelahan tinggi dan sangat tinggi.

\section{Tabulasi Silang Shift Kerja dengan Kelelahan Kerja Operator CC di PT. X}

Kelelahan kerja ini dibagi menjadi empat yaitu kelelahan kerja rendah, kelelahan kerja sedang, kelelahan kerja tinggi, dan kelelahan kerja sangat tinggi. Tetapi tidak ada responden yang mengalami kelelahan kerja tinggi dan sangat tinggi. Tabel 4 menunjukkan bahwa operator yang mengalami kelelahan kerja rendah paling banyak adalah pada shift pagi yakni berjumlah 24 operator $(52,17 \%)$. Operator CC yang mengalami kelelahan sedang paling banyak adalah pada shift pagi dan shift malam yakni sebanyak $40 \%$. Pada shift kerja sore hari kelelahan kerja yang terjadi cenderung rendah yakni sebanyak $28,3 \%$, hal ini apabila dibandingkan dengan kelelahan kerja sedang yang dialami oleh operator CC yang bekerja pada shift sore hanya sebanyak 20\%. Shift malam menunjukkan kelelahan kerja sedang sebanyak $40 \%$, bila dibandingkan dengan operator CC yang mengalami kelelahan kerja rendah menunjukkan selisih sebesar $21,4 \%$. Shift pagi menunjukkan lebih banyak yang mengalami kelelahan kerja rendah, sedangkan shift malam menunjukkan kecenderungan mengalami kelelahan kerja sedang. Semakin malam operator CC ini bekerja maka kelelahan kerja yang terjadi akan semakin meningkat. hal ini dapat dilihat bahwa shift pagi menunjukkan banyak operator CC yang mengalami kelelahan rendah, pada shift sore kelelahan rendah terjadi tetapi kelelahan sedang juga

Tabel 5. Tabulasi Silang Lama Waktu Tidur dengan Kelelahan Kerja pada Operator CC di PT. $\mathrm{X}$

\begin{tabular}{|c|c|c|c|c|c|c|}
\hline \multirow{3}{*}{$\begin{array}{l}\text { Lama } \\
\text { Waktu } \\
\text { Tidur } \\
\text { (Jam) }\end{array}$} & \multicolumn{4}{|c|}{ Kelelahan Kerja } & \multirow{2}{*}{\multicolumn{2}{|c|}{ Total }} \\
\hline & \multicolumn{2}{|c|}{ Rendah } & \multicolumn{2}{|c|}{ Sedang } & & \\
\hline & $\mathbf{n}$ & $\%$ & $\mathbf{n}$ & $\%$ & $\mathbf{N}$ & $\%$ \\
\hline$\leq 6,5$ & 23 & 50,0 & 3 & 60,0 & 26 & 51,0 \\
\hline$>6,5$ & 23 & 50,0 & 2 & 40,0 & 25 & 49,0 \\
\hline Total & 46 & 100,0 & 5 & 100,0 & 51 & 100,0 \\
\hline
\end{tabular}

meningkat, pada shift malam kelelahan kerja yang terjadi adalah kelelahan sedang.

\section{Tabulasi Silang antara Lama Waktu Tidur dengan Kelelahan Kerja Operator CC di PT. X}

Tabel 5 menunjukkan bahwa paling banyak operator mempunyai waktu tidur $\leq 6,5$ jam dalam sehari. Pada penelitian ini menunjukkan bahwa operator yang mengalami kelelahan kerja rendah mempunyai waktu tidur $\leq 6,5$ jam dan $>6,5$ jam sebanyak $50 \%$. Operator yang mempunyai waktu tidur $\leq 6,5$ jam lebih banyak yang mengalami kelelahan kerja sedang yaitu bisa dilihat dari selisih antara kelelahan kerja rendah dan sedang sebanyak $10 \%$ pada operator yang mengalami kelelahan kerja sedang mempunyai lama waktu tidur paling banyak $60 \%$ pada lama waktu tidur $\leq 6,5$ jam. Kelelahan rendah tidak terjadi perbedaan antara lama waktu tidur yang dimiliki oleh operator. Kelelahan kerja sedang menunjukkan adanya kecenderungan mengalami kelelahan sedang pada operator yang lama waktu tidurnya lebih sedikit.

\section{Tabulasi Silang antara Shift Kerja dengan Lama Waktu Tidur Operator CC di PT. X}

Tabel 6 dapat dilihat bahwa paling banyak operator yang memiliki waktu tidur $>6,5$ jam adalah operator pada shift pagi sebanyak $48,0 \%$ dan juga paling banyak operator yang mempunyai waktu tidur $\leq 6,5$ jam adalah operator pada shift pagi sebanyak $53,8 \%$. Pada shift pagi lebih banyak memilih waktu tidur yang kurang dibanding dengan shift sore dan shift malam. Shift malam menunjukkan bahwa waktu tidur yang dimiliki lebih banyak.

Tabel 6. Tabulasi Silang Shift Kerja dengan Kelelahan Kerja pada operator CC di PT. X, Mei 2017

\begin{tabular}{lcccccc}
\hline \multirow{2}{*}{$\begin{array}{l}\text { Shift } \\
\text { Kerja }\end{array}$} & \multicolumn{3}{c}{ Lama Waktu Tidur (jam) } & \multicolumn{2}{l}{ Total } \\
\cline { 2 - 5 } & \multicolumn{2}{c}{$\mathbf{\mathbf { 6 , 5 }}$} & \multicolumn{2}{c}{$\mathbf{\mathbf { 6 , 5 }}$} & & \\
\cline { 2 - 6 } & $\mathbf{n}$ & $\mathbf{\%}$ & $\mathbf{n}$ & $\mathbf{\%}$ & $\mathbf{N}$ & $\mathbf{\%}$ \\
Pagi & 14 & 53,8 & 12 & 48,0 & 26 & 51,0 \\
Sore & 8 & 30,8 & 6 & 24,0 & 14 & 27,5 \\
Malam & 4 & 15,4 & 7 & 28,0 & 11 & 21,6 \\
\hline Total & 26 & 100,0 & 25 & 100,0 & 51 & 100,0 \\
\hline
\end{tabular}




\section{PEMBAHASAN}

\section{Kelelahan Kerja}

Hasil penelitian yang telah dilakukan terhadap operator CC di PT. X menunjukkan bahwa operator CC memiliki peluang mengalami kelelahan kerja dengan berbagai kategori kelelahan. Berdasarkan hasil pengukuran kelelahan kerja yang telah dilakukan sebanyak $90,2 \%$ operator CC mengalami kelelahan kerja rendah dan yang mengalami kelelahan kerja sedang sebanyak 9,8\%.

Menurut Tarwaka (2015), kelelahan kerja adalah suatu perlindungan dalam tubuh untuk mengatasi kerusakan yang lebih lanjut dan dapat pulih kembali setelah istirahat. Kelelahan kerja ini dapat dipengaruhi oleh berbagai macam faktor individu itu sendiri ataupun faktor dari luar individu. Faktor individu mulai dari umur, jenis kelamin, status pernikahan, tingkat pendidikan, masa kerja, lama kerja, gizi kerja ataupun faktor dari luar individu seperti kondisi lingkungan kerja, beban kerja, sikap kerja dan lain sebagainya.

Hasil penelitian menunjukkan bahwa kelelahan kerja yang dialami oleh operator CC ini cenderung rendah yakni sebesar 90,2\% mengalami kelelahan rendah tetapi kelelahan yang sedang juga tidak dapat dihindarkan. Operator CC yang mengalami kelelahan yang sedang sebesar 9,8\%. Kelelahan sedang yang terjadi juga tidak dapat diremehkan karena kelelahan ini dapat memengaruhi produktivitas kerja dan absentisme operator bahkan hingga terjadinya kecelakaan kerja.

Operator CC melakukan pekerjaannya dalam 8 jam dalam sehari secara bergantian dan juga dibutuhkannya konsentrasi dan kewaspadaan untuk mengangkut peti kemas dari kapal ke dermaga ataupun sebaliknya dan juga dengan posisi kerja yang duduk sedikit membungkuk dalam waktu yang lama dan juga kerja yang statis membuat operator CC mengalami kelelahan.

Operator menjalankan alat container crane ini dilakukan secara bergantian maka kelelahan rendah yang lebih banyak bisa saja terjadi dan hanya beberapa operator yang mengalami kelelahan kerja rendah. Hal ini juga menyebabkan kelelahan tinggi atau bahkan kelelahan sangat tinggi tidak terjadi pada operator CC di PT. X.

Kelelahan kerja bisa diatasi dengan adanya waktu istirahat disela-sela beban kerja yang tinggi. Operator CC di PT. X ini bekerja rata-rata 4 jam dalam sehari dan 4 jam sisanya digunakan untuk beristirahat.

\section{Shift Kerja}

Pekerja yang menjalani shift kerja ialah tenaga kerja yang bekerja di luar jam kerja normal dalam kurun waktu tertentu. Operator CC ini bekerja dengan sistem kerja shift. Pembagian shift kerja pada operator CC ini terdapat 3 shift kerja yaitu shift kerja pagi, sore dan malam. Shift kerja dapat memengaruhi circadian rhythm tubuh operator CC dan juga menyebabkan kelelahan dan timbulnya rasa kantuk. Keadaan yang lelah akan membuat menurunnya konsentrasi dalam bekerja.

Shift kerja dapat memengaruhi keselamatan dan kesehatan pekerja. Dengan adanya circadian rhythm fungsi tubuh seperti, suhu tubuh, kemampuan mental, denyut nadi, pada siang hari akan meningkat dan pada malam hari digunakan sebagai pemulihan. Seseorang yang bekerja pada malam hari maka pemulihan ini akan terganggu.

Dari Tabel 4 diketahui bahwa yang shift kerja yang mengalami kelelahan sedang pada shift pagi dan shift malam. Apabila dilihat kembali shift malam mengalami kelelahan sedang sebanyak 18,7\% dari 11 operator. Sedangkan shift kerja pagi dan sore mengalami kelelahan sedang sebanyak 7,1\%.

Selama malam hari, fungsi dari fisiologi tubuh mempunyai nilai yang rendah, sebagai contoh yaitu suhu inti dan detak jantung mengawali irama diurnal tubuh, hal ini didukung oleh ketidak aktifnya pada malam hari dan puasa. Pada siang hari aktivitas puncak umumnya bertepatan dengan nilai tinggi dan fungsi internal. Pengamatan irama diurnal ini didapatkan dari hasil internal (endogenus) dan eksternal (exogenus) yang terjadi. Apabila terjadi ketidakseimbangan di antara keduanya maka akan muncul masalah kesehatan.

Pekerjaan dengan sistem kerja shift ini mempunyai beberapa keuntungan dan kerugian. Keuntungan dari adanya kerja shift ini ialah proses produksi dapat dilakukan terus-menerus tanpa henti. Dalam hal ini apabila terdapat kapal yang bersandar di dermaga pada malam hari sekalipun tetap dapat dilayani untuk melakukan bongkar muat peti kemas dan tidak menghambat pekerjaan pada pagi harinya. Tetapi kerja shift juga mempunyai kerugian yaitu terganggunya pola tidur, stres kerja, kelelahan kerja dan bahkan terjadinya kecelakaan kerja. Hal ini terjadi pada operator CC di PT. X ini. Kecelakaan kerja yang terjadi pada shift malam pada tahun 2015 mencapai 17 kasus.

Dampak shift kerja yang lainnya yaitu pada aspek fisiologis pekerja yang harus menyesuaikan diri dengan perubahan waktu selama 24 jam. Dengan 
terganggunya fisiologis pekerja akan menyebabkan gangguan pola tidur, gangguan gastrointestinal dan gangguan kesehatan lainnya. aspek psikologis akibat shift kerja seperti ketidakpuasan, meningkatnya stress kerja, aspek kinerja yakni tingkat kesalahan yang meningkat, dan tingkat kecelakaan meningkat pada malam hari.

\section{Lama Waktu Tidur}

Hasil penelitian yang dilakukan di PT. X bahwa lama waktu tidur pada operator $\mathrm{CC} \leq 6,5$ jam menunjukkan kecenderungan terjadinya kelelahan kerja. waktu untuk tidur sangatlah penting untuk memulihkan kondisi dari keadaan stres yang dialami oleh pekerja setiap harinya. Dengan waktu tidur yang baik dapat memperbaiki kondisi psikologi pekerja yang diakibatkan karena adanya stres akibat dari pekerjaannya. National sleep foundation (2015) menganjurkan seseorang yang berusia dewasa untuk tidur antara 7-9 jam per harinya. Waktu tidur yang terlalu lama dapat menyebabkan seseorang mengalami obesitas dan juga diabetes.

Tidur berfungsi untuk pemulihan fisiologi dan psikologis individu. Tidur yang nyenyak dapat bermanfaat untuk memelihara fungsi jantung. Kurangnya waktu untuk tidur dapat menyebabkan adanya perasaan lelah, mudah terangsang, gelisah, lesu, apatis, kehitaman di sekitar mata, kelopak mata bengkak, konjungtiva merah, sakit kepala dan juga sering menguap dan mengantuk (Suriansyah, 2011)

\section{Shift Kerja dengan Kelelahan Kerja}

Menurut Claire (2014) menyatakan bahwa salah satu penyebab kelelahan adalah gangguan tidur yang disebabkan karena kurangnya waktu untuk tidur serta gangguan pada circadian rhythm yang diakibatkan karena jet lag atau shift kerja. Kelelahan kerja menjadi masalah yang dapat mengganggu kualitas hidup tenaga kerja. Kelelahan yang terjadi ini dapat menyebabkan menurunnya konsentrasi pada saat menjalankan pekerjaannya. Kelelahan kerja yang terjadi juga dapat mengakibatkan adanya kecelakaan kerja.

Hasil penelitian diketahui bahwa kelelahan yang dialami oleh operator CC sebanyak 90,2\% kelelahan kerja rendah dan 9,8\% kelelahan kerja sedang. Operator yang mengalami kelelahan kerja sedang $40 \%$ diantaranya adalah operator yang bekerja pada shift pagi dan juga shift kerja malam. Dilihat dari total operator container crane pada shift kerja malam lebih banyak yang mengalami kelelahan kerja, 2 dari 11 operator $18,7 \%$ mengalami kelelahan kerja sedang. Semakin malam operator bekerja, maka kelelahan yang timbul akan semakin tinggi atau bahkan sangat tinggi.

Kelelahan kerja sedang ini tidak dapat diremehkan, karena dengan adanya kelelahan kerja sedang ini apabila dibiarkan terus menerus akan terakumulasi dalam tubuh dan menjadikannya sebagai kelelahan kronis.

Waktu kerja 24 jam dibagi menjadi dua hingga shift kerja. Pembagian shift kerja sangatlah penting. Karena pada tenaga kerja yang bekerja dengan shift malam circadian rhythm akan terganggu. Tenaga kerja yang bekerja pada malam hari harus tidur selama siang hari untuk mempertahankan kondisi tubuhnya dalam keadaan siap untuk bekerja di malam hari.

Shift kerja yang diberlakukan di PT. X yaitu 2-2-2 yakni pergantian shift dilakukan setiap 2 hari dan jadwal libur hanya 1 hari. hal ini sejalan dengan penelitian Setyawati (2010) bahwa terdapat dua macam shift kerja, yaitu shift kerja berputar (berotasi) dan juga shift kerja permanen. Rotasi kerja yang pendek akan lebih baik dibanding rotasi kerja yang panjang dan juga sebaiknya dihindarkan dari kerja malam secara terus-menerus.

Rotasi kerja yang baik yaitu 2-2-2 yang dibagi menjadi kerja pada pagi hari dua kali, pada sore hari dua kali dan juga pada malam hari dua kali. Dapat juga menggunakan rotasi 2-2-3, yaitu kerja di pagi hari selama dua kali, sore hari dua kali, dan pada malam hari tiga hari berturut-turut. Hal ini harus diikuti dengan waktu istirahat lebih dari 24 jam atau istirahat selama dua hari.

Tujuan dari dibentuk adanya shift kerja ialah agar proses produksi dapat berjalan secara terus menerus. Dengan adanya shift kerja dapat mengubah fungsi tubuh yang teratur menjadi tidak teratur, yang pada pagi hingga siang hari diatur untuk melakukan pekerjaan dan pada malam hari diatur untuk beristirahat.

Menurut Wagstaff, et al (2011), mengatakan bahwa pada saat bekerja pada malam hari mungkin muncul rasa kantuk yang dikhawatirkan akan timbul adanya kecelakaan kerja. Rasa kantuk ini dirasakan ketika jam kerja memasuki jam pada awal pagi hari, yaitu sekitar pukul 05.00-07.00. Pada PT. X kecelakaan kerja yang terjadi seringkali pada jam di awal pagi. Sedangkan rasa kantuk pada pagi hari berada pada tingkat rasa kantuk sedang, dan susah mengalami rasa kantuk pada bekerja di sore hari. Menurut Akerstedt (2006), bahwa pekerjaan sebagai operator menunjukkan adanya kejadian tertidur saat bekerja pada malam hari. Salah satu efek dari shift 
kerja adalah pola tingkat kelelahan yang berkaitan dengan pola tidur

Tabel 5 menunjukkan bahwa operator CC yang pada shift kerja malam hari mempunyai waktu tidur $28 \%$ pada $>6,5$ jam. Hal ini bisa terjadi karena sebelum ataupun sesudah bekerja dianjurkan untuk beristirahat tidur. Pada operator yang beristirahat sesudah bekerja yaitu pada operator yang menjalankan alat container crane di waktu pertama. Sedangkan pada operator yang beristirahat sebelum bekerja yaitu pada operator yang menjalankan container crane kedua. Adanya pergantian jam kerja setelah 4 jam menjadikan operator mempunyai waktu tidur lebih banyak.

Lamanya waktu tidur yang dialami oleh operator $>6,5$ jam lebih banyak pada shift pagi. Shift kerja pagi mempunyai waktu tidur lama karena jumlah operator pada shift pagi lebih banyak dari shift yang lainnya karena pada shift ini terdapat dua grup yang berbeda. Shift malam menunjukkan bahwa operator yang bekerja pada malam hari mempunyai lama waktu tidur yang $\leq 6,5$ jam. Kurangnya tidur pada operator khususnya pada operator yang mempunyai shift kerja malam hari apabila dibiarkan terus menerus maka akan terakumulasi secara terus-menerus sehingga mengalami kelelahan dalam menjalankan pekerjaannya dan juga tingkat kewaspadaan operator dalam menjalankan alat container crane ini menurun, sehingga dapat berakibat pada terjadinya kecelakaan kerja yang diakibatkan karena menurunnya kewaspadaan oleh terjadinya kelelahan kerja yang dialami.

Hal ini sejalan dengan pendapat Wulandari (2014) bahwa adanya gangguan tidur terhadap kelelahan kerja yang mempunyai hubungan yang signifikan. Tubuh manusia memerlukan waktu untuk beristirahat yang cukup dan tepat untuk melakukan perbaikan sel yang berada dalam tubuh seseorang pada saat tertidur, akan tetapi apabila seseorang memiliki waktu tidur yang kurang menyebabkan seseorang mengalami gangguan tidur yang akan memengaruhi terjadinya kelelahan kerja pada seseorang.

Hal ini tidak sesuai dengan National Sleep Foundation (2015) bahwa usia dewasa disarankan untuk tidur selama 7-9 jam per harinya. Waktu tidur berfungsi untuk menjaga fungsi tubuh tetap bugar dan siap untuk menjalankan aktivitas pekerjaannya pada pagi harinya. Kualitas tidur mencerminkan kepuasan terhadap tidur dan dapat menyegarkan tubuh keesokan harinya (Silvanasari, 2012).
Kualitas tidur yang baik, maka orang tersebut tidak memperlihatkan perasaan lelah, mudah terangsang dan gelisah, lesu dan apatis, kehitaman di sekitar mata, kelopak mata bengkak, konjungtiva merah, perhatian terpecah, sakit kepala dan sering menguap atau mengantuk. Sehingga kelelahan kerja dapat dihindari atau bahkan dicegah dengan melakukan istirahat yang cukup. Kurangnya waktu tidur terjadi pada operator yang memiliki shift kerja pada malam hari. Hal ini menunjukkan bahwa shift kerja pada malam hari mempunyai waktu tidur yang kurang (Zuliana, 2013).

Hal ini sejalan dengan penelitian yang dilakukan Liana (2012) menyimpulkan bahwa adanya pengaruh kelelahan kerja dengan shift kerja menunjukkan hasil yang signifikan. Hasil uji koefisien kontingensi antara shift, bahwa shift yang paling berpengaruh terhadap kelelahan kerja yaitu shift malam. Seluruh bagian tubuh manusia aktif bekerja pada sore hari dan pada malam hari dalam keadaan istirahat. dalam tubuh manusia ini mengatur pola kerja dan istirahat, secara alamiah tubuh mengatur sistem circadian rhythm. Internal timekeeper ini yang mengatur adanya berbagai aktivitas tubuh yaitu bekerja, tidur dan pencernaan makanan.

Selama melakukan pekerjaannya operator CC mengalami kelelahan kerja yang terjadi tidak hanya disebabkan karena adanya shift kerja tetapi juga didukung dengan faktor lain. Seperti karakteristik individu, lingkungan kerja, beban kerja, dan lain sebagainya.

\section{SIMPULAN}

Kelelahan kerja yang terjadi pada operator CC cenderung rendah yakni sebanyak $90,2 \%$ operator mengalami kelelahan kerja rendah. Lama waktu tidur $\leq 6,5$ jam cenderung mengalami kelelahan kerja. Shift kerja memberikan pengaruh terhadap terjadinya kelelahan kerja yang dialami oleh operator CC. Shift kerja malam menunjukkan adanya kecenderungan untuk mengalami kelelahan kerja.

\section{DAFTAR PUSTAKA}

Åkerstedt, T., 2006. Searching for the Countermeasure of Night-Shift Sleepiness. SLEEP [e-Journal] 29 (1) :pp. 19-20

Arini, S. Y., Dwiyanti, E., 2015. Analisis Faktor yang Berhubungan dengan Terjadinya Kelelahan Kerja pada Pengumpul Tol di Perusahaan Pengembang 
Jalan Tol Surabaya. The Indonesian Journal Of Occupational Safety and Health, [e-Jurnal] 4 (2): pp. $113-122$

Caruso, C. C., 2014. Negative Impacts of Shift work and Long Work Hours. Rehabil Nurs [e-Journal] 39(1): pp. 16-25

Fadda, P., Meloni, M., Fancello, G., Pau, M., Medda, A., Pinna, C., Rio, A. D., Lecca, L. I., Setzu, D., Leban, B., 2015. Multidisciplinary Study of Biological Parameters and Fatigue Evolution in Quay Crane Operator. Procedia Manufacturing [e-Journal] 3 (2015): pp. 3301-3308

Faiz, N., 2014. Faktor-Faktor yang Berhubungan dengan Kelelahan Kerja pada Pekerja Bagian Operator SPBU di Kecamatan Ciputat Tahun 2014. Skripsi. Jakarta: Fakultas Kedokteran dan Ilmu Kesehatan Universitas Islam Negeri Syarif Hidayatullah

Hidayat, A. T., 2011. Analisis Pengaruh Shift Kerja Terhadap Beban Kerja Pada Pekerja di PT. Primarindo Asia Infrastructure, Tbk. Skripsi. Bandung: Fakultas Teknik Universitas Islam Bandung.

International Labour Organization., 2013. The Prvention OfOccupational Diseases. Switzerland: International Labour Organization

Kusumawardani, L., 2012. Pengaruh Shift Kerja terhadap Kelelahan Perawat Wanita Bagian Rawat Inap di Rumah Sakit Dr. Oen Surakarta. Skripsi. Surakarta: Fakultas Kedokteran Universitas Surakarta

National Sleep Foundation., 2005. How To Spot Sleep Apnea Early. Washington: National Sleep Foundation

National Sleep Foundation., 2015. Sleep-Wake Cycle: Its Physiology and impact on health. Sleep. Washington: National Sleep Foundation
Santoso, G., 2013. Ergonomi Terapan. Jakarta: Prestasi Pustaka Raya

Setyawati, L., 2010. Selintas Tentang Kelelahan Kerja. Yogyakarta: Amara Books

Silvanasari, I.A., 2012. Faktor-Faktor yang Berhubungan dengan Kualitas Tidur yang Buruk pada Lansia di Desa Wonojati Kecamatan Jenggawah Kabupaten Jember. Skripsi. Jember: Universitas Jember

Steenken, D., Stefan V. O. B., Robert, S., 2004. Container Terminal Operation and Operations Research: A Classification and Literature Review. OR Spectrum [e-Journal] 26: p. 3-49

Suma'mur.,2009. Higiene Perusahaan dan Kesehatan Kerja (Hiperkes). Jakarta: CV Sagung Seto

Suriansyah., 2012. Pola Tidur yang Baik. http:// www.suriansyah. com/2012/12/pola-waktu-tiduryang-baik

Tarwaka., 2015. Ergonomi Industri: Dasar-Dasar Ergonomi dan Implementasi di Tempat Kerja. Surakarta: Harapan Press.

Wagstaff, A. S., DavMed, M. D., Sigtad, J. A., 2011. Shift and Night Work and Long Working Hours - A Systematic Review of Safety Implication. Scand J Work Environment Health [e-Journal] 37 (3): pp. 173-185

Wulandari, I. G. A. N., Luh Made, I. S. H. A., 2015. Hubungan Gangguan Tidur dengan Kelelahan pada Sistem Kerja Bergilir (Shift) Malam terhadap Karyawan Minimarket 24 Jam di Kota Denpasar. Jurnal Ergonomi Indonesia [e-Journal] 1 (1): pp.51-60

Zuliana, N., 2013. Hubungan Karakteristik Individu dan Faktor Pekerjaan Terhadap Tingkat Perasaan Kelelahan Kerja Perawat Rawat Inap (Rumah Sakit Umum Daerah (RSUD) Dr. Iskak Tulungagung). Skripsi. Surabaya: Fakultas Kesehatan Masyarakat Universitas Airlangga 